\title{
Students' Motivation for Learning Ghanaian Languages in the University
}

\author{
Ernest Nyamekye*, Daniel Baffour-Koduah \\ Department of Arts Education, Faculty of Humanities and Social Sciences Education, University of Cape Coast, Cape Coast, Ghana \\ Email address: \\ nyamekyeernest86@gmail.com (E. Nyamekye), everlastingwhytersnr@gmail.com (D. Baffour-Koduah) \\ ${ }^{*}$ Corresponding author
}

\section{To cite this article:}

Ernest Nyamekye, Daniel Baffour-Koduah. Students' Motivation for Learning Ghanaian Languages in the University. International Journal of Applied Linguistics and Translation. Vol. 7, No. 2, 2021, pp. 43-52. doi: 10.11648/j.ijalt.20210702.13

Received: February 11, 2021; Accepted: February 24, 2021; Published: April 29, 2021

\begin{abstract}
This study sought to examine students' motivation for studying Ghanaian languages in University of Cape Coast. It adopted a descriptive survey design with a sample of 144 students in University of Cape Coast. The statistical methods employed were descriptive and inferential statistics. Mann-Whitney U test and Wilcoxon Signed Rank test were used to test the hypotheses set to guide the study. It was revealed that students were motivated by both instrumental and integrative factors. However, it was revealed that students were more motivated by integrative factors than instrumental factors. Also, there were no differences between male and female students concerning how motivated they are in studying Ghanaian languages. Finally, it was revealed that students who believed they were pursuing Ghanaian languages because it has been prescribed as part of the university's requirement for fulfilling the Bachelor of Arts Education honour were less motivated while students who are pursuing it because it is their desired programme of study were more motivated. Contrary to the preconceived notion that Ghanaian language students are using their programme of study as an easy route to attain good grades, it could be concluded that they are rather impelled by the desire to get a better knowledge of the Ghanaian culture.
\end{abstract}

Keywords: Motivation, Integrative Motivation, Instrumental Motivation, Language of Instruction, Language in Education Policy

\section{Introduction}

\subsection{The Study of Ghanaian Languages}

The use of Ghanaian languages as instructional media gained recognition in the Ghanaian educational system during the days of the Christian missionaries [23]. In the early 90 s, several policies were made to consider the use of the local languages as Language of Instruction (LOI) for the first three years of education, while English-only instruction was enforced in subsequent levels of education in Ghana. A notable policy that emphasised the use of local languages at the lower level of education and a transition to the Englishonly instruction was the Guggisberg's Ordinance in the year 1925. This policy emphasised that the local languages should be used as the LOI in the first three years of education and be made a subject of study at the upper level (primary 4 upwards) of education. It is, however, surprising that after the administration of the nation fell in the hands of Ghanaians, there were inconsistencies regarding the implementation of the Language in Education policy of Ghana [20].

In 1951, the Accelerated Development Plan (ADP) was introduced by the Conventions People Party who had taken over the administration of the country. The introduction of the ADP also reiterated the position of the ADP 1925 Guggisberg's ordinance on the use of Ghanaian languages as media of instruction in the first three years of education [17]. However, after reviewing the Accelerated Development Plan in the year 1957 the use of the Ghanaian languages was eliminated from all level of education. The compulsory use of the English language only was, therefore, emphasised [3]

In 1996, the Kampong Committee, tasked by the National Liberation Council to review the government's job in the education sector, found that the English-only policy was not being implemented as proposed in many schools. It was, therefore recommended that there must be reversed to the old policy which advocated for the use of local languages in the first three years of education. The National Liberation 
Council (NLC), the then incumbent government, rejected the proposal. However, consideration was made for local languages to be used in Primary 1. This, further, throws more light on the fact that English-medium of instruction has always been favoured by the successive Ghanaian governments [20].

Despite the rejection of the recommendation of Kwapong's Committee under the NLC government, it was later implemented when the Progress Party (PP) won the election. This led to the establishment of the Ghanaian languages school to get trained teachers who could use various Ghanaian languages as instructional medium in the classroom. According to Clermont [4], the development of the Ghanaian languages school failed due to lack of funds to enforce the reformation of the curricula. As a result, schools continued relying on the use of British textbooks, hence the use of the local languages as the instructional medium fell short.

The instability with regards to the choice of language to be used in the classroom appears to be settled after the introduction of the National Accelerated Literacy Programme (NALAP) in the year 2006. The NALAP, developed by the National Literacy Task Force (NLTF) of Ghana Education Service (GES), was tasked to investigate the low literacy skills which they consider to be one causes of poor education in Ghana [6]. According to the GES.

The task force recommended the adoption of the National Literacy Acceleration Programme (NALAP), an instructional approach which provides teachers and pupils of the Lower Primary level (KG 1 - P3) with quality literacy materials, effective instruction and public support to read and write in their local language and English. The methodology seeks to make pupils literate in their local language for a smooth transition to English. Therefore, by P3, it is expected that the pupils would be fully bilingual (GES REPORT, 2010, P. 1).

The NALAP outlined clear guidelines for the implementation of the Language in Education policy. Coupled with the provision of all necessary learning materials, it was expected that teachers stick strictly to the implementation plan of the NALAP. It was expected that at the upper primary level, teachers would use only English as the language of instruction [5]. The brief review of the development of the Ghanaian language in Education Policy highlights the fact that the use of English as LOI has been highly favoured whiles the use of the Ghanaian language as the LOI has been relegated. It is not surprising that most students in the secondary and tertiary schools despise the study of the Ghanaian languages [21].

\subsection{Current Languages Studied in Ghana}

The Ghanaian educational structure is composed of 2-9-34 system. According to Edu-Buandoh and Owu-Ewie [21], schooling in Ghana begins with "a 2 years kindergarten education, 6 years of primary education and 3 years of Junior High School education" (p. 3). After primary education is 3 years of Senior High School and 4 years of tertiary education. These authors emphasised that two languages (English and
Ghanaian language) have been officially declared languages of instruction. All these languages are also taught as core subjects at the basic level of education, however, the Ghanaian language is treated as an elective subject at the SHS level. This implies an early-exit transitional model of bilingual education. Thus, the Ghanaian language is being used as the language of instruction from the first three years of basic education with a gradual transition to English instruction at the upper level of primary education.

Presently, Ghanaian languages are studied as elective subject in Senior High Schools. Fante, Nzema, Twi, Ga, Dangme, Gonja, Kasem, Dagbani, Gurene, Dagaare, Ewe, Sisala are the specific languages offered in various SHS. The choice of language to study is dependent on the geographical location. Thus, the choice of language being studied in a given SHS depends on the dominant tribe within which the school is located. However, in the Universitylevel, various languages are offered as a programme of study. Specific universities that offer Ghanaian languages are University of Education, Winneba, Kwame Nkrumah University of Science and Technology, University of Ghana and the University of Cape Coast. The University of Education, Winneba appears to be the leading University that offers all the Ghanaian language courses. "They offer BA in Fante, Nzema, Twi, Ga, Dangme, Gonja, Kasem, Dagbani, Gurene, Dagaare, Ewe and Sisala. They also offer MPhil and MA in Akan (Fante and Twi), Ewe and MA/MPhil in Ghanaian Language Studies (Ga, Dangme, Gonja, Kasem, Dagbani, Gurene, Dagaare and Nzema" [21].

The University of Cape Coast offers BA, MA and MPhil in Akan (Fante and Twi), Ewe and Ga. Also at the Department of Arts Education, Ghanaian language is part of the subject areas being offered. KNUST also offers undergraduate courses in Akan, while the University of Ghana offers BA and MPhil in Ga, Akan and Ewe.

\subsection{Attitudes Toward the Study of Ghanaian Languages}

Pursuing Ghanaian languages as a programme of study in tertiary institutions has, over the years, become a psychological hurdle to students. Literature [21] has it that in various Senior High Schools, students studying Ghanaian languages have been stereotyped as academically weak students who turn to easier options to attain good grades. This situation could be attributed to the prestige attached to the study of English and other foreign languages. Due to the prestigious nature of the English language in the Ghanaian educational system, it has always been perceived as the only language fit for use as the language of education and the only language worth to be invested in [14]. The consequences of this prestige attached to the study of English language is the unfavourable attitude of people towards the native languages in Ghana. It is, therefore, not surprising that the Ghanaian languages are depicted as languages unfit for use in official and administrative domains. It is for this reason that teachers, lecturers and professors of the local languages are demeaned and undermined by colleagues who erroneously perceive them to be 'second-rate' colleagues in academia. This, 
according to Guerini [14], is an attitude that affects students. According to Nyamekye and Baffour-Koduah [19], this misconception hovering around the study Ghanaian languages in various academic institutions has gained roots in the minds of parents to the extent that they feel overly disappointed when they realize that their wards are pursuing native languages as a programme of study at the University. It is thus, not surprising that in the year 1994 the study of the Ghanaian languages in the Senior Secondary School as a core subject was abolished. The abolishment was associated with the misconception that the mass failure of students in English and other subjects were a result of the overuse of Ghanaian languages as the medium of communication and instruction. According to Edu-Boandoh and Owu-Ewie [21] the stereotype attached to the study of Ghanaian languages in schools has crippled the study of Ghanaian languages as it is believed that this has caused a considerably low enrolment of Ghanaian languages students.

Despite the stereotype attached to the study of Ghanaian languages in the High Schools and tertiary institutions, there appears to be a growing interest in pursuing Ghanaian languages in higher educational institutions for the past decade. Enrollment into the Ghanaian languages programme appears to be increasing at an increasing rate. For instance, in 2018/2019 academic year, out of 590 Bachelor of Arts Education (B. Ed Arts) students who were enrolled on the School of Educational Development and Outreach (SeDO) sandwich programme at St Louis University College of Education, 33\% of them took Ghanaian Language as their major programme of study while $37 \%$ took English as their major programme of study. French $(6.7 \%)$, History $(10 \%)$ and Religious and Moral Education (12.7\%) recorded the lowest enrolment. Also in the 2019/2020 academic year, a total of 479 B. Ed Arts students admitted at the Offinso University College of Education, 35\% of these students were Ghanaian language students while $36 \%$ were English language students. Just like the previous academic year French (7\%), History (12\%), and Religious and Moral Education (10\%) recorded the lowest enrolment. This, therefore, substantiates the claim that the study Ghanaian language in tertiary institutions appears to have stimulated the interest of many. It is, therefore, imperative to conduct a study of this nature to look into the motivation of students for studying Ghanaian languages at the University. Based on the growing interest in the study of Ghanaian indigenous languages, this study seeks to examine the sources of motivation for students of the Ghanaian languages in the University of Cape Coast. It, specifically, seeks to examine the level of instrumental and integrative motivation of Ghanaian language students, examine the form of motivation that largely impels students to study Ghanaian languages at the university, examine any possible differences between the forms of motivation for Ghanaian language students based on gender, examine the differences between the motivation of students who willingly applied for the Ghanaian language programme and those who perceive it to be part of the university's requirement for fulfilling the Bachelor of Arts
Education honour.

\subsection{Research Questions and Hypotheses}

The study will be guided by the following research questions and hypotheses.

i. What is the level of students' motivation for studying Ghanaian languages in the University of Cape Coast?

ii. H0: There is no significant difference between integrative and instrumental motivation of students studying Ghanaian languages.

iii. H0: There is no significant difference between students' integrative motivation based on gender.

iv. H0: There is no significant difference between students' instrumental motivation based on gender.

v. H0: There is no significant difference between the motivation of students who willingly applied for the Ghanaian language programme and students who consider the programme as part of the University's requirement.

The rest of the paper delves into related literature relevant to this current study, research methodology, and the presentation and discussion of the findings of the study.

\section{Literature Review}

\subsection{The Concept of Motivation}

Motivation appears to be one of the most influential factors in learning. Its role in acquiring knowledge is to accelerate the learning process. As a complex phenomenon, it has always been subjected to different conceptualizations because scholars find it challenging to reach a consensus regarding what motivation entails. According to Gardner [11], motivation has three basic concepts that characterize it. These are effort, desire and effect. With regards to language learning, he believes that effort, as a concept in motivation refers to the time and the drive the student dedicates to learning a particular language, while the desire indicates how proficient a student wants to be in a particular language. Effect, on the other hand, relates to the emotions a student attaches to a particular language he is learning. Also, Gardner [12] describes motivation as a mixture of an effort and a willingness to achieve the goal of language learning. In other words, the motivation to learn a new language refers to the degree to which the person attempts or seeks to learn a language out of the urge to do so and the pleasure gained throughout this role.

According to Brown [10], conceptualizing motivation is not an easy task. This challenge, according to him, could be ascribed to the lack of theories to explain motivation. However, there seems to be a lot of research literature available on the role of motivation in language learning. This has, therefore, solve the scarcity of definitions on the concept of motivation.

Learning and motivation are separate concepts, however, the successfulness of learning, to some extent, hinges on motivations. Parsons, Hinson and Brown [22] substantiate 
this claim as they point out that learning and motivation complement each other to achieve something. That is to say, knowledge can only be acquired effectively in a motivating learning environment. Drawing on this, it could be said, as Xiaoquing and Qiufang [32] postulates, that motivation influences the extent to which one would excel or fail in his/her attempt to learn a language. Furthermore, motivation has been conceptualized as a phenomenon the impacts on a learner's ability, and also an essential means to overcoming a learning hurdle [31].

An overarching definition of [8]sees motivation as "the attribute that moves us to do or not to do something". Similarly, motivation has also been perceived as an internal activity that has control over human behaviour [26]. Based on the different conceptualizations of motivation, it could simply be concluded that motivation in learning is any internal or external force that impels someone to accomplish a given task.

\subsection{Forms of Motivation}

Generally, literature describes two forms of motivation. These include intrinsic and extrinsic [13]. The ability to inspire oneself internally to perform desired task is intrinsic motivation. This applies to internal guided behaviour. It allows a learner to accomplish a task which is not for social gain but rather based on personal desire and pleasure. Extrinsic motivation refers to the driving power of a person triggered by external items. In other words, an external incentive controls the momentum to make one work or do something $[13,16]$.

Irrespective of the forms of motivation, which have all been supported by literature as important determinants of learning, they all affect the actions of students, how they accomplish objectives and predicts the outcome of their learning $[16,30]$ note that good relations and successful school control lead to promoting the participation and encouragement of students in the classroom activities. For instance, encouraging children to engage in classroom conversation and determining how to achieve a task will provide them with intrinsic motivation rather than forcing them to perform an academic exercise. Also, as learners are empowered and allowed to ask questions, they are capable of thinking and inspiring themselves to actively participate in an academic exercise. The use of verbal persuasion, body language, motion, and gesture by teachers will also catch the attention of pupils and assist them to analyze things rapidly. Learners feel happy and able to learn and work efficiently when the above are available [2].

In relation to language learning, scholars believe that motivation for learning a language is shaped by their ultimate goal for learning the language. For this reason, Harmer [15] classified motivation into two categories; that is long term goals and short term goals. Short term goal, according to these authors relates to one's desire to achieve something immediately. For instance, a student may be motivated to learn a language for examination purposes. On the other hand, a long term goal has to do with learning to achieve career objectives such as one's desire to secure a job in the future.

Based on the overall goal for learning a language, motivation has also been categorized into two. According to Brown [9], motivation for learning a foreign language could be integrative or instrumental. Integrative motivation refers to the type of motivation that is shape by a student's inner willingness to be proficient in a particular language in order to be identified with a particular culture. That is, students are motivated to learn a language in order to communicate with native or other proficient speakers of the language. This type of motivation has a bearing to intrinsic motivation which Arnold [7] defines as learning 'having its own reward'. Students with this type of motivation learn for their own good. Learning, to a student with intrinsic motivation, is not a means to gain a reward or to avoid punishment. Along this line, integrative motivation appears to be an inner desire to learn a language for communicative purposes. On the other hand, instrumental motivation refers to the desire of students to learn a language in order to achieve materialistic goals. That is to say, students with instrumental motivation learn a language because of anticipated benefits that go with it. Such students learn the language intending to pass exams, secure a job, get opportunities to study abroad, and other external sources of benefits. This type of motivation also falls in line with extrinsic motivation which is dependent on external outcomes such as rewards and punishments. According to Nguyen [18], a student who is motivated by external factors do not learn with great intention, they are rather moved by the rewards or punishments attached to acquiring a specific language.

\subsection{The Role of Motivation in Language Learning}

The role of motivation in language learning cannot be overemphasized. No doubt, Spolsky [29], asserts that there is a higher possibility that a motivated student is more likely to learn quickly than a less motivated one. A student with no motivation approach learning with absolute reluctance, they are likely to cause a degree of disobedience and also cause a whole lot of discipline problems. On the flipped side, students with high motivation towards a specific learning task tend to pay maximum attention, participate actively and also contribute in any learning environment.

The link between motivation and learning has been verified by various studies. Of the many variables that can predict learner failure or bad learning results, lack of motivation is the primary cause for most pupils. Motivation can provide a person with an internal drive that contributes to action towards the completion of a specific purpose or mission. It also empowers one to be industrious in effectively accomplishing their goals [16, 24]. Wiseman and Hunt [30] concluded that students must be well inspired to learn because motivation is the secret to unlocking their minds to assimilate what they learn. Motivation, according to Ryan and Deci [25], is a basic ingredient and an inevitable recipe for student engagement in learning. That is to say, student engagement is not an end in itself but rather a means to academic excellence. [1] Has reiterated this assertion as he 
points out that motivation is a central determinant of the well-being of a learner. Motivation is related to the willingness of students to succeed in the learning process. If motivation affects students' education and outcomes, it is important to analyze how pupils' motivation for learning is influenced.

Extensive studies have been conducted on the association between motivation and language learning. In a relevant study, Zhang et al. [33] examined the relationship between English students' motivation and their language proficiency in universities in Shaanxi Province, China. Data collected through a questionnaire was analysed using regression analysis. It was revealed in this study that both instrumental and integrative motivation of students positively influenced their second language competence. In a similar study, Siriluck and Sirithip [28] sought to examine the association between English undergraduate students' motivation and their language proficiency. It was indicated in this study that these undergraduate students were more triggered by integrative factor. They were more encouraged by the desire to integrate into the English culture than students with a low level of English proficiency. However, the study revealed no significant difference in instrumental factors between these groups.

There seems to be limited literature in terms of students motivation in learning a language in Ghana. However, Sarfo [27] explored factors that motivate students to study English at the university level. His data for the study were gathered from the University of Cape Coast and the University of Ghana. It was found, in this study, that students' motivations for studying English are more instrumental/utilitarian than integrative. Although this study is relevant, it cannot be generalized to this current study because it focused on English only. With regards to Ghanaian languages, little is known about students' motivation. This leaves a literature gap which necessitates further explorations.

\section{Methodology}

This study adopted the descriptive survey design which falls into quantitative research domain. This design was considered appropriate because the study sought to take into consideration a representative sample in order to generalize the findings of the study to the entire population. The study took into consideration all Ghanaian language students in the University of Cape Coast. Specifically, all regular students and students enrolled under the School of Educational Development and Outreach (SeDO) sandwich programme were considered. A total of 600 students were identified and included in the study. Given the nature of the study population, stratified random sampling was used to select 144 students for the study. A self-developed questionnaire was administered to University of Cape Coast regular students and students enrolled on the SeDO sandwich programme. Data collected through the questionnaire were coded and analysed with the Statistical Package for Social Sciences (SPSS v. 21). Data were analysed by computing the means and standard deviation of the Likert scale items. Mann-Whitney $U$ test and Wilcoxon signed-ranks test was also used to test the hypothesis that guided the study.

\section{Results and Discussions}

\subsection{Interpretation of Mean Values of Agreement}

Table 1 gives a summary of the mean scores of the Likert Scale items indicating the extent to which students are motivated towards the study of Ghanaian languages in the University of Cape Coast.

Table 1. Interpretation of mean scores.

\begin{tabular}{ll}
\hline Mean Score & Level of Motivation \\
\hline $1.0-1.9$ & Very Low \\
$2.0-2.9$ & Low \\
$3.0-3.9$ & Moderate \\
$4.0-4.9$ & High \\
5.0 & Very High \\
\hline
\end{tabular}

\subsection{Description of Background Data}

This section of the data analysis comprises three sections. The first section looks at the characteristics of the respondents of the study, while the next section gives a detailed analysis of the research data based on the research objectives. Table 2 sums up the general information of the participants of the study.

Table 2. Demographics Data Respondents.

\begin{tabular}{|c|c|c|c|}
\hline \multirow{2}{*}{ Institution } & \multicolumn{3}{|c|}{ Gender } \\
\hline & Male & Female & Total \\
\hline University of Cape Coast (UCC Regular) & 24 & 27 & 51 \\
\hline School of Educational Development and Outreach (UCC sandwich, Offinso Centre) & 23 & 35 & 58 \\
\hline School of Educational Development and Outreach (Ucc Sandwich, St Loius Centre) & 19 & 16 & 35 \\
\hline Total & 66 & 78 & 144 \\
\hline
\end{tabular}

Source: Field Data (2020)

A total of 144 students were sampled for the study. Out of the 144 respondents, a total of 51 students comprising 24 male and 27 females were regular students of the University of Cape Coast. On other hand, a total of 93 students were enrolled in the School of Educational Development and
Outreach (SeDO) sandwich programme of the Institute of Education, University of Cape Coast. Out of the 93, 23 males and 35 females were sampled in the Offinso Centre, while 19 males and 16 females were sampled in Saint Loius Centre.

Students' perceived willingness to Study Ghanaian 
languages in the University

Table 3 summarizes the perceived willingness of students studying the Ghanaian language programme. It sought to find students who willingly applied to be admitted as Ghanaian language students and those who considered it as a requirement of the university.

Table 3. Perceived willingness to Study Ghanaian languages.

\begin{tabular}{lll}
\hline Statement & Frequency & Percentage \\
\hline I am pursuing the Ghanaian language programme because it is my desired programme of study & 121 & 84.0 \\
I am pursuing the programme because it is a university requirement & 23 & 16.0 \\
Total & 144 & 100 \\
\hline
\end{tabular}

Source: Field data (2020)

The table indicates that out of the 144 students, $84 \%$ willingly applied to pursue the Ghanaian language programme in the university, however, $16 \%$ of the students indicated that they are pursuing the programme because it has been provided as part of the requirement for fulfilling the Bachelor of Arts Education degree.

\subsection{Findings}

This section presents the findings based on the various research objectives set to guide this study. The first research question examines the motivation level of students studying Ghanaian languages at the University. It attempts to find whether or not they are highly motivated in pursuing their programme of study. The research hypotheses, on the other hand, examine the form of motivation that drives students the most, the difference between the forms of motivation for studying Ghanaian languages with respect to gender and the difference between the motivation of students who believed they are pursuing the programme because it is their desired programme and those who believe it is a University requirement.

\subsubsection{Students'Level of Motivation for Learning Ghanaian Languages}

Tables 4 and 5 present the instrumental and integrative motivations for studying Ghanaian languages in the University of Cape Coast.

Table 4. Instrumental Motivation for studying Ghanaian language.

\begin{tabular}{|c|c|c|c|}
\hline Statement & M & (SD) & Motivation Level \\
\hline I am learning Ghanaian language because it is the easiest programme I can excel in & 2.78 & 1.5 & Low \\
\hline Learning a Ghanaian language will improve the chances of getting a job easily in Ghana & 4.31 & 0.85 & High \\
\hline Learning Ghanaian language will help me easily pass in examinations and further my education & 3.95 & 0.94 & Moderate \\
\hline Learning Ghanaian language will enable me to have the edge over others in securing a job & 4.45 & 0.64 & High \\
\hline Learning a Ghanaian language will help me get enrolment into masters easily & 4.08 & 0.92 & High \\
\hline Overall Instrumental motivation & 3.91 & 0.70 & Moderate \\
\hline
\end{tabular}

Source: Field Data (2020)

The table indicates that students' motivation for studying Ghanaian language is high. Factors such as learning Ghanaian language to improve the chances of getting a job, giving them the edge over others in competing for a job and getting easy admissions to further education highly motivated students studying Ghanaian languages at the university. However, studying Ghanaian language to easily excel in examinations and also because it is the easiest programme were factors that had the least ratings in terms of the level of motivation. This, therefore, erode the perception of people that students pursuing Ghanaian languages in the university are compelled to do so because it appears to be the easiest programme of study they can excel in. On average, the level of instrumental motivation for studying Ghanaian language is moderate $(\mathrm{M}=3.91, \mathrm{SD}=0.70)$.

Table 5. Integrative Motivation for Studying Ghanaian Language at the University.

\begin{tabular}{|c|c|c|c|}
\hline Statement & M & (SD & Motivation Level \\
\hline I want to understand the Ghanaian culture very well & 4.69 & 0.62 & High \\
\hline I want to improve my language proficiency in the Ghanaian language & 4.54 & 0.73 & High \\
\hline $\begin{array}{l}\text { Learning Ghanaian language will equip me with the knowledge to discuss to others the grammatical } \\
\text { structure of the language }\end{array}$ & 4.67 & 0.47 & High \\
\hline Learning the Ghanaian language will help me attain a native-like accent & 4.63 & 0.56 & High \\
\hline $\begin{array}{l}\text { Learning Ghanaian language will equip me with the knowledge and skills to teach others the uniqueness } \\
\text { of the Ghanaian Culture }\end{array}$ & 4.61 & 0.57 & High \\
\hline
\end{tabular}

Source: Field data (2020)

In terms of integrative factors, the study found that across all the items students appear to be highly motivated. That is, their motivation for studying Ghanaian languages in the university are highly integrative. The variable with the highest mean value is students' willingness to understand the Ghanaian culture very well $(\mathrm{M}=4.69)$, followed by their 
willingness to be knowledgeable on the grammatical structures of the Ghanaian language. The overall mean (4.63) indicates that Ghanaian language students in the University are highly motivated by instrumental factors.

Summary of the overall motivation level of students

Table 6. Overall motivation level.

\begin{tabular}{llll}
\hline Form of Motivation & Mean & $\begin{array}{l}\text { Standard } \\
\text { Deviation }\end{array}$ & $\begin{array}{l}\text { Motivation } \\
\text { Level }\end{array}$ \\
\hline Integrative Motivation & 4.63 & 0.46 & High \\
Instrumental & 3.91 & 0.70 & Moderate \\
Overall Motivation & 4.27 & 0.52 & High \\
\hline
\end{tabular}

Based on the statistics presented in the table it appears that the overall motivation of the students for learning Ghanaian languages is high at the Mean value of (4.27). The findings of the study fall in line with the findings of Hedge (2000) in that Ghanaian language students appears to be motivated by both integrative and instrumental factors.

\subsubsection{The Difference Between Students' Instrumental and Integrative Motivation for Studying Ghanaian Languages in the University}

This research objective sought to find out whether or not there exists a difference between integrative and instrumental motivation of students studying Ghanaian language at the University. To achieve this, a Willcoxon Signed rank test was run to examine the forms of motivation that compel students to pursue the Ghanaian language programme. The results of the Wilcoxon Signed Ranks test show that the median rank of integrative motivation (Median=4.80) was statistically higher than the median rank of instrumental motivation (Median=4.0), $\mathrm{Z}=-9.71, \mathrm{p}<0.00$. Based on the test results, the null hypothesis cannot be retained. The test results imply that Ghanaian language students are more motivated by integrative factors than instrumental factors. This finding substantiates the findings of Siriluck and Sirithip [28] that proficient English language users are integratively motivated in the study of the English language. It also points out the fact that unlike English language students in Ghanaian universities [27], students of various Ghanaian languages are more motivated by integrative factors than instrumental. Thus, their motivation for studying Ghanaian language in the University of Cape Coast is based on their willingness to integrate into the Ghanaian culture.

\subsubsection{Difference Between Students Integrative Motivations Based on Gender}

This research objective sought to examine any differences between males and females' motivation for studying Ghanaian language in the University. Based on the skewness of the data, a Mann-Whitney $U$ test was conducted to compare the integrative motivation of females to males. The results of the study showed that there is no significant difference between the integrative motivation of students based on gender $(p=0.067)$ Hence the null hypothesis is retained. This, therefore means that both male and female students studying Ghanaian language have a similar level of integrative motivation.

\subsubsection{Difference Between Students Instrumental Motivation Based on Gender}

The research objective on the other hand sought to examine the possible differences that may exist between male and female students on instrumental motivation. To achieve this the Mann-Whitney $U$ test was run to compare the mean ranks of males' instrumental motivation to that of females. The results indicated that the difference between males and females' instrumental motivation was not significant $(\mathrm{p}=0$. 15). This implies that the instrumental motivation of both male and female Ghanaian language students is at the same level.

\subsubsection{The Difference in the Motivation of Students Who Willingly Applied to Pursue Ghanaian Language and Those Who Perceive It as a University Requirement}

This research hypothesis sought to find whether or not a difference exists between the level of motivation of students who believe they willingly applied to study Ghanaian languages in the University of Cape Coast and those who feel they are pursuing it because it has been provided as part of University's requirement to fulfilling a Bachelor of Arts Education degree. A Mann-Whitney U test was therefore run to compare the motivation of both groups. Mann-Whitney $U$ test was conducted to test this hypothesis. The results show that there is a statistically significant difference between the motivation of students who willingly applied to study Ghanaian language (median=4.40 $\mathrm{n}=121$ ) and those who considered it to be part of the University's requirement to fulfilling the Bachelor of Education (Arts) and Bachelor of Arts degree (BA) (median=3.70, $n=23), U=842.00, p<0.003$ (2 tailed). Hence, the null hypothesis is rejected. This, therefore, implies that students who willingly applied to study Ghanaian language in the University are more motivated than those who perceive it to be a university requirement.

\section{Conclusion}

The study sought to examine the motivation level of students pursuing the various Ghanaian languages in the University of Cape Coast. The purpose of the study was informed by the recent increase in the number of students pursuing the Ghanaian languages programme in the University of Cape Coast. The study found that students studying Ghanaian languages are highly motivated. However, it could be concluded that students' motivation for studying Ghanaian languages are triggered by integrative factors than instrumental factors. Thus, their ultimate goal for studying Ghanaian languages is to get a better understanding of their culture and the desire to effectively use the language for interactive and communicative purposes. Contrary to the pertinent view of people that the study of the Ghanaian languages in the University is due to their desire to attain good grades, the study concludes that such a factor does not motivate 
students since it appeared to be the least motivating factor in this study. In terms of gender, the study concludes that both male and female students are all motivated to studying Ghanaian language. The study further concludes that students who believe they willingly applied to study Ghanaian languages in the university are more motivated than those that felt that the Ghanaian language was offered as part of the university's requirement for fulfilling the Bachelor of Arts Education and the Bachelor of Arts honour.

\section{Recommendations}

Based on the findings of the study, it is recommended that to ensure that students are motivated in pursuing a local language as programme, they must be made to attend interviews to assess their motivation level towards a particular programme prior to their admission to the University. This could help improve their academic outputs since motivation is associated with academic output.

Also, there must be orientations for students in various high schools on the need to study the local languages in the University. This would shape their attitude and perception of the study of Ghanaian languages. Once high school students are conditioned to appreciate the essence of learning their native languages in the university, they would be highly motivated in pursuing it as a programme of study. The reason for this recommendation is that attitude and motivation are somewhat intertwined. Hence, students with a positive attitude towards the Ghanaian languages programme would be more motivated to pursue it.

\section{Appendix A}

\section{Questionnaire}

THE MOTIVATION FOR LEARNING GHANAIAN LANGUAGES IN THE UNIVERSITY OF CAPE COAST

I entreat you to help research factors that motivate students to further the study of Ghanaian languages in the University of Cape Coast. Your contributions and sincerity in the response you provide will greatly influence the study in diverse ways. I appreciate every bit of your time spent on this study. Thank You

SECTION A

Kindly respond to the following by checking the brackets provided.

1. Gender: Male [ ] Female []

2. Institution

University of Cape Coast (Sandwich, Offinso Centre) [ ]

University of Cape Coast (Sandwich, St Louis Centre) [ ]

University of Cape Coast (Regular) [ ]

3. Programme Status of Students

Ghanaian Language as Major [ ]

Ghanaian Language as Minor [ ]

4. Perceived state of enrolment on the Ghanaian language Programme.

It was a University requirement [ ]

I willingly applied to study Ghanaian Language in the university [ ]

SECTION B

The motivation for furthering the study of Ghanaian Languages

Please respond to the following statements by checking Strongly Disagree (SD), Disagree (D), Neutral (N), Agree (A) and Strongly Agree (SA)

Table 7. Questionnaire on Students' Motivation for Studying Ghanaian Languages

\begin{tabular}{|c|c|c|c|c|c|c|}
\hline & Statement & SD & D & $\mathbf{N}$ & A & SA \\
\hline 5 & I am learning Ghanaian language because it is the easiest programme I can excel in & & & & & \\
\hline 6 & Learning a Ghanaian language will improve the chances of getting a job easily in Ghana & & & & & \\
\hline 7 & Learning Ghanaian language will help me easily pass in examinations and further my education & & & & & \\
\hline 8 & Learning Ghanaian language will enable me to have the edge over others in securing a job & & & & & \\
\hline 9 & Learning a Ghanaian language will help me get enrolment into masters easily & & & & & \\
\hline 10 & I want to understand the Ghanaian culture very well & & & & & \\
\hline 11 & I want to improve my language proficiency in the Ghanaian language & & & & & \\
\hline 12 & $\begin{array}{l}\text { Learning Ghanaian language will equip me with the knowledge to discuss to others the grammatical structure } \\
\text { of the language }\end{array}$ & & & & & \\
\hline 13 & Learning the Ghanaian language will help me attain a native-like accent & & & & & \\
\hline 14 & $\begin{array}{l}\text { Learning Ghanaian language will equip me with the knowledge and skills to teach others the uniqueness of the } \\
\text { Ghanaian Culture }\end{array}$ & & & & & \\
\hline
\end{tabular}




\section{Appendix B}

Table 8. Test results of Wilcoxon Signed Ranks Test for difference between students instrumental and integrative motivation.

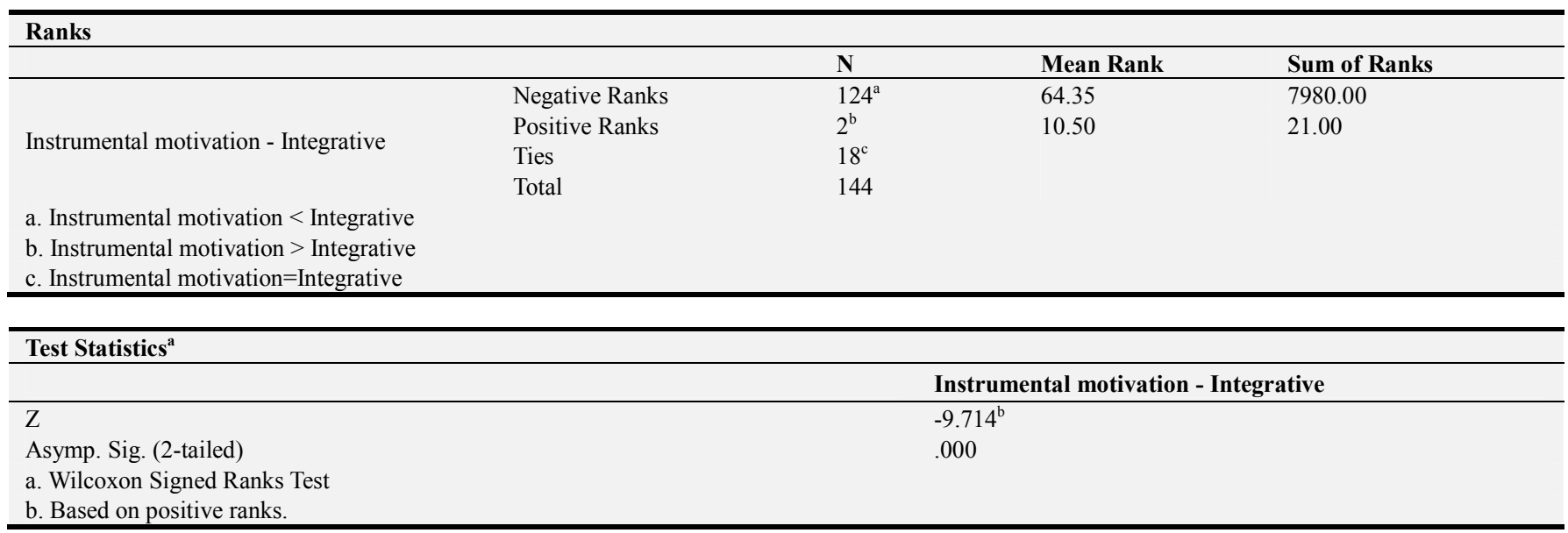

Table 9. Test results of Mann Whitney U test for the difference between students integrative and instrumental motivations based on gender.

\begin{tabular}{llll}
\hline Ranks & & & Mean Rank \\
\hline & Gender & N & 79.04 \\
Integrative & male & 66 & 66.97 \\
& female & 78 & 5216.50 \\
& Total & 144 & 5223.50 \\
Intrumental motivation & male & 66 & 5136.50 \\
& female & 78 & 57.99 \\
\hline & Total & 144 & \\
\hline Test Statistics & & & \\
\hline & & & \\
\hline Mann-Whitney U & & Integrative & Instrumental motivation \\
Wilcoxon W & & 2142.500 & 2222.500 \\
Z & & 5223.500 & 5303.500 \\
Asymp. Sig. (2-tailed) & -1.829 & -1.416 \\
a. Grouping Variable: Gender & .067 & .157 \\
\hline
\end{tabular}

Table 10. Mann Whitney U test results for the difference between the motivation of students who willingly applied for the Ghanaian language programme and students who consider the programme as part of the University's requirement.

\begin{tabular}{llll}
\hline Ranks & & & \\
\hline & enrollment state & N & Mean Rank \\
\hline \multirow{3}{*}{ overall } & willingly applied & 121 & 77.04 \\
& University requirement & 23 & 48.61 \\
& Total & 144 & 9322.00 \\
\hline
\end{tabular}

\begin{tabular}{ll}
\hline Test Statistics $^{\mathbf{a}}$ & \\
\hline & \\
\hline Mann-Whitney U & overall \\
Wilcoxon W & 842.000 \\
Z & 1118.000 \\
Asymp. Sig. (2-tailed) & -3.006 \\
a. Grouping Variable: enrollment state & .003 \\
\hline
\end{tabular}

\section{References}

[1] Adedigba, O. (2015). The influence of aesthetic school environment on children's motivation for learning and school attendance in Ilorin Metropolis. Journal of Early Childhood Association of Nigeria, 5, 363-374.

[2] Akpakwu, S. O. (2008). Essentials of educational management. Jalim Press Nigeria Ltd. Andoh-Kumi, K. (2002). Literacy in the medium of I nstruction and the quality of teaching and learning. A paper presented at the fourth inter-University Colloquium on the co-existence of languages in West Africa University of Education, Winneba.

[3] Ankrah, O. T. (2015). Education experts' perceptions of the Ghanaian language policy and its implementation. University of Lapland. 
[4] Ansah, G. N. (2014). Re-examining the fluctuations in language in-education policies in post-independence Ghana. Multilingual Education, 4, 12.

[5] Anyidoho, A. (2018). Shifting Sands: Language Policies in Education in Ghana and Implementation Challenges. Ghana Journal of Linguistics, 7 (2), 225-243.

[6] Arnold, J. (2000). Affect in language learning. Cambridge: Cambridge University Press.

[7] Broussard, S. C., \& Garrison, M. E. (2004). The relationship between classroom motivation and academic achievement in Elementary-School-Aged children. Family and Consumer Sciences Research Journal, 33 (2), 106-120.

[8] Brown, H. D. (2000). Principles of Language Learning and Teaching. $\left(4^{\text {th }}\right.$ ed.). New York: Addison Wesley Longman. Chang.

[9] Dörnyei, Z. (2001). New themes and approaches in second language motivation research. Annual review of applied linguistics, 21 (1), 43.

[10] Gardner, R. C. (1983). Learning another language: a true social psychological experiment. Journal of language and social psychology, 2, 219-240.

[11] Gardner, R. C. (1985). Social psychology and second language learning: The role of attitudes and motivation. London: Edward Arnold Publishers.

[12] Gbollie, C., \& Keamu, H. P. (2017). Students' academic performance: role of motivation, strategies, and perceived factors hindering Liberian junior and senior high school learning. Education Research International, 2021, 1-11 https://doi.org/10.1155/2017/1789084.

[13] Guerini, F. (2008). Multilingualism and language attitudes in Ghana: a preliminary survey.

[14] Harmer, J. (1991). The practice of English language teaching. London: Longman.

[15] Marcou, A., \& Philippou, G. (2005). Motivational beliefs, self-regulated learning and mathematical problem solving. Group for the Psychology of Mathematics Education, 3, $297-$ 304.

[16] McWilliam, H. O. A., \& Kwamena-Poh, M. A. (1975). The development of education in Ghana: An outline. Longman.

[17] Nguyen, T. M. (2019). Do extrinsic motivation and organisational culture additively strengthen intrinsic motivation in online knowledge sharing?. VINE Journal of Information and Knowledge Management Systems.

[18] Nyamekye, E., \& Baffour-Koduah, D., (2021). The Language of Instruction Dilemma in Ghana: Making a Case for the Various Ghanaian Languages. International Journal of Research and Innovation in Social Science (IJRISS), 5 (1), $146-150$.
[19] Owu-Ewie, C. (2006,). The language policy of education in Ghana: A critical look at the English-only language policy of education. In Selected proceedings of the 35th annual conference on African linguistics (pp. 76-85). Somerville, MA: Cascadilla Proceedings Project.

[20] Owu-Ewie, C., \& Edu-Buandoh, D. F. (2014). Living with negative attitudes towards the study of L1 in Ghanaian Senior High Schools (SHS). Ghana Journal of Linguistics, 3 (2), 125 .

[21] Parsons, R. D., Hinson, S. L., \& Sardo-Brown, D. (2001). Educational psychology: A practitioner-researcher model of teaching. Wadsworth/Thomson Learning.

[22] Quarcoo, M. A. (2014). Language policy and language of education in Ghana: A reality or an illusion. Wisconsin Journal, 4, 49-59.

[23] Reeve, J. (2006). Extrinsic rewards and inner motivation. In C. M. Evertson \& C. S. Weinstein (Eds.), Handbook of classroom management: Research, practice, and contemporary issues (pp. 645-664). Lawrence Erlbaum Associates.

[24] Ryan, R. M. \& Deci, E. L. (2009). Promoting self-determined school engagement: Motivation, learning, and well-being. In K. R. Wentzel \& A. Wigfield (Eds.), Handbook of motivation at school. (pp. 171196). New York: Routledge.

[25] Salvin, J. D. (2006). Effect of achievement motivation on scholastic achievement among high school girls. Recent Researches in Education \& Psychology. 10, 1-4.

[26] Sarfo, E. (2012). Ghanaian university students' attitudes towards English. International review of social sciences and humanities, 4 (1), 86-99.

[27] Siriluck, W. \& Sirithip, P. (2002). Integrative motivation, instrumental motivation, and English achievement among students in the Faculty of Arts. Unpublished master's thesis, School of Language and Communication. National Institute of Development Administration.

[28] Spolsky, B. (1990). Conditions for second language learning. Hong Kong: Oxford University Press.

[29] Wiseman, D., \& Hunt, G. (2008). Best practice in motivation and management in the classroom (2nd ed). Charles Thomas.

[30] Xiaoqing, Q. (2003) (2nd Ed). Motivation perspectives, motivation theories in psychology and implications for L2 motivation researchers. Foreign Language Research 4, 74-79.

[31] Xiaoqing, Q., \& Qiufang, W. (2002). The internal structure of learning motivation for non-English majors. Foreign Language Teaching and Research, 1, 51-58.

[32] Zhang, H., Dai, Y., \& Wang, Y. (2020). Motivation and second foreign language proficiency: The mediating role of Foreign Language Enjoyment. Sustainability, 12 (4), 1302. 